\title{
Cutting and breaking in Äiwoo: Event integration and the complexity of lexical expressions*
}

ÅSHILD N/ESS

Abstract

This paper examines the lexical encoding of events of "cutting and breaking" in the Oceanic language Äiwoo. It shows that this language differs from previously described languages in this domain in several ways: in having complex "cut and break" forms consisting of two bound elements referring to distinct aspects of the cut and break event; in integrating these forms into a cline of lexicalisation vs. serialisation, arguably reflecting a conceptual-semantic continuum of event integration; and in violating previously suggested generalisations concerning the behaviour of verbs of cutting and breaking in inchoative alternations. It shows that lexicalisation may clearly be a matter of degree, and that the degree to which an event is construed as being constituted by independent subevents vs. subevents which cannot occur independently may be directly reflected in the type of formal expression a language provides to describe it. Furthermore, it suggests that the distinction between "cut" and "break" expressions, assumed in some of the literature to be a fairly straightforward bipartition, may in fact be more of a cline. The paper thus demonstrates the complexity of the cognitive domain of cutting and breaking events and the range of strategies that may be employed by a language in describing them.

Keywords: Cut and break verbs; Lexicalisation; Event categorisation; Wordhood.

\section{Introduction}

The semantic domain of "cut and break" verbs - verbs referring to acts bringing about a "separation in material integrity" of an object in the terms of Hale

* Email: 〈Aashild.Naess@newcastle.edu.au〉. 
\& Keyser (1987) — has been subject to fairly systematic crosslinguistic study in recent years, most particularly in the project reported in Majid and Bowerman (2007). The main interest has been in how events of "cutting and breaking" are categorised cognitively, as evidenced by the types of events which may be referred to by the same term: which semantic parameters are found to distinguish between different types of cutting and breaking events? Furthermore, the morphosyntactic properties of "cutting and breaking" expressions have been studied from a crosslinguistic perspective e.g. by Bohnemeyer (2007), partly on the basis of the generalisation made by Guerssel et al. (1985) that "break" verbs should be able to participate in the inchoative but not the conative alternation (I broke the branch > The branch broke, but not *I broke at the branch), while "cut" verbs should show the opposite patterning. Bohnemeyer shows that this behaviour partly depends on the morphosyntactic structure of the expressions involved, in the sense that expressions which specify both the causing event and its effect on an object (such as serial verbs in Mandarin or particle-verb constructions in German) do not undergo either alternation.

This paper will discuss the expression of cutting and breaking events in Äiwoo, a little-studied Oceanic language. It will show that Äiwoo differs from previously described cases in several respects.

Firstly, forms describing acts of cutting and breaking in Äiwoo are systematically bimorphemic, but in the core case neither of the morphemes has an independent use. ${ }^{1}$ Though morphologically complex, Äiwoo cut and break expressions are grammatically and phonologically single words.

Secondly, cut and break forms in Äiwoo can be seen as being located at or near the endpoint of a continuum of morphological integration whose other endpoint is that of serialisation of clearly independent verbs; it will be argued that this reflects a conceptual-semantic continuum of event integration.

Thirdly, Äiwoo cut and break verbs do not obey Guerssel et al.'s generalisation concerning the inchoative alternation in the strict sense, but neither do they exactly violate it; instead, the language simply makes no distinction between "cutting" and "breaking" verbs in inchoative forms.

With respect to the question of which types of events may be represented in language by single lexical items (Bohnemeyer et al. 2007, Koptjevskaja-Tamm et al. 2007), the Äiwoo data demonstrates that, like the concept "single event", the concept "single lexical item" may itself be a matter of degree. I will suggest that the Äiwoo language exploits this parallelism by using constructions showing progressively greater formal integration to refer to events of progressively

1. In other words, Äiwoo cut and break forms are neither parallel to serial verb expressions as those found in Mandarin (Chen 2007) nor to German particle-verb constructions as discussed by Bohnemeyer (2007). 
greater semantic integration. Furthermore, the complex semantic interplay between the two parts of an Äiwoo cut and break verb illustrates that the distinction between "cut verbs" and "break verbs" is more complex than a simple difference in how the act of destruction is carried out by the agent. While the two parts of an Äiwoo cut and break verb can be identified as denoting the causing event carried out by the agent, and the effect of this event on the object, respectively, it does not follow that a form where the initial element describes a causing event involving an instrument such as a knife or axe will necessarily denote an act which can be felicitously described as "cutting". The manner in which the object breaks - e.g. whether it snaps cleanly or shatters-clearly also plays a role, showing that it is only the interaction between the two parts of the verb that allow for an accurate interpretation of the event described. Since any "cause" morpheme can in principle be combined with any "effect" morpheme in Äiwoo (with some restrictions discussed in 3.1), the categorisation of individual forms as either "cut verbs" or "break verbs" is largely a matter of degree in this language, in that a form may refer to an event which shows characteristics both of "cutting" and of "breaking".

\section{Language and data}

\subsection{The Äiwoo language}

The Äiwoo language is spoken in the Reef Islands group in the easternmost region of the Solomon Islands. It belongs to the so-called Reefs-Santa Cruz group of languages, which until recently were assumed to have a Papuan substrate; it should be noted that "Papuan" is not a family term but is negatively defined as those languages in the Pacific that are not Austronesian. Such a substrate would set these languages apart from the other languages of the region, which are purely Austronesian. However, recent work has shown that the evidence for a Papuan substrate is flawed, and that the languages in fact belong to a first-order subgroup of Oceanic (itself a subgroup of Austronesian), along with the languages of nearby Utupua and Vanikoro islands (Næss 2006, Ross and Næss 2007, Næss and Boerger 2008).

The language has around 8,000 speakers in all (1999 census), including speakers living away from the Reef Islands, on nearby Santa Cruz or in the national capital Honiara. Its nearest neighbour is the Polynesian Outlier language Vaeakau-Taumako (Pileni), spoken in the Outer Reef Islands; Äiwoo and Vaeakau-Taumako speakers have presumably been in regular contact since the arrival of the latter in the area, estimated at some $800-1,000$ years ago, and there is some evidence that Äiwoo speakers may traditionally have been bilingual in Vaeakau-Taumako (Næss and Jenny 2011). At present, the main 
language used for intergroup communication is the English-lexifier Solomon Islands Pijin.

\subsection{Data}

The data used in this study was collected through fieldwork in the Reef Islands, and with Äiwoo speakers in the Solomon Islands' capital Honiara, during a total of about five months in 2004-2005. It includes data elicited from two speakers with the video stimulus set known as "Kids' Cut and Break", developed at the Max Planck Institute for Psycholinguistics (Bowerman and Majid 2003). This is not the same stimulus used for the studies reported in Majid and Bowerman (2007), but it was designed for a similar purpose, and consists of short film clips depicting people carrying out cut and break-type acts such as cutting a piece of paper with scissors, tearing a cloth in half, chopping a branch off a tree, etc. I had chosen to bring the "Kids" " version of the stimulus tool because it was a newer version and considered more suitable if one wanted to run the test with children as well as adults; it is not, however, intended only for use with children, and my consultants were adults. As I was not specifically looking for data on cut and break verbs at the time, but simply ran the clips as a means of getting my consultants started and eliciting what I anticipated would be a good set of data to start working on the structure of the language, I neglected to ask a number of questions which would have greatly enriched the data, and this is an obvious weakness of the analysis below. The data further includes my notes from a 2-hour session organised by a group of speakers in 2005 as a response to my questions about words for cut and break-type events and their uses, where a practical demonstration was given by means of props such as sticks, rocks, hammers, knives, tins, etc.; as well as data from other stimulus-based recording sessions (see 5.2 below) and from narrative texts which make up a total of about 6 hours of recorded speech.

\subsection{Grammatical preliminaries}

The following aspects of Äiwoo grammar are relevant for the exposition below.

Firstly, Äiwoo marks the person and number ${ }^{2}$ of subjects and, in some cases, objects, by affixation on the verb; intransitive verbs take subject prefixes (1),

2. Äiwoo person marking is organised according to a so-called minimal-augmented system, where 'you and I' ('1st + 2nd' person) functions as a distinct person category. It patterns like the other persons in that it can be "pluralised", but since its "singular" form refers to two people, the terms "minimal" and "augmented" are used instead of "singular" and "plural" for such systems. The "unit-augmented" number refers to minimal number plus one, i.e. two people for the 1st, 2nd and 3rd persons, but three for the 1+2nd person: 'you and I plus one'. Person affixes on verbs do not show a distinct unit-augmented form in Äiwoo; instead, a suffix $-l e$ is added to the augmented form of the verb. 
while transitive verbs take subject (and object) suffixes (2). $3^{\text {rd }}$ person minimal objects are formally unmarked, as are $3^{\text {rd }}$ person minimal subjects unless the object of a transitive verb with a 3 MIN subject is other than $3^{\text {rd }}$ person minimal, as exemplified in (2d).

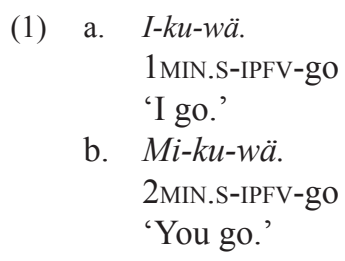

(2) a. I-kää-no.

PFV-know-1MIN.A

'I know it/him/her.'

b. I-kää-mu.

PFV-know-2MIN.A

'You know it/him/her'.

c. I-kää-nеe-ти.

PFV-know-1MIN.A-2MIN.O

'I know you.'

d. I-kä̈̈-gu-i.

PFV-know-3MIN.A-3AUG.o

'He knows them.'

Table 1. Äiwoo intransitive subject prefixes

\begin{tabular}{lll}
\hline & Minimal & Augmented \\
\hline 1 & $i-$ & $m e-$ \\
$1+2$ & $j i-$ & $d e-$ \\
2 & $m i-/ m u-$ & $m i-$ \\
3 & $\varnothing$ & $l i-\mid l u-$ \\
\hline
\end{tabular}

Table 2. Äiwoo transitive subject suffixes

\begin{tabular}{lll}
\hline & Minimal & Augmented \\
\hline 1 & $-n o /-n e e$ & $-n g o(p u)$ \\
$1+2$ & $-j i$ & $-d e$ \\
2 & $-m u$ & $-m i$ \\
3 & $\varnothing /-g u$ & $-i$ \\
\hline
\end{tabular}


Secondly, verbs describing events involving two participants from a semantic point of view come in two forms: one formally intransitive, taking subject prefixes, and one transitive, taking subject suffixes. The intransitive forms are usually followed by a noun referring to a notional object, but this noun does not pattern like a syntactic object of its clause, as it cannot be crossreferenced on the verb and is postverbal, unlike objects of transitive verbs which, if nominal, are usually preverbal. I refer to these verbs, which take intransitive person marking but occur with a notional object noun, as "semi-transitive".

Semi-transitive verbs are used in reference to generic or habitual acts, or acts with multiple or nonreferential objects. There is no regular derivation forming transitive from semi-transitive verbs or vice versa, but pairs of transitive and semi-transitive verbs show recurrent patterns of alternation suggesting that they originate in a derivational process. ${ }^{3}$
a. Si-vângâ
$k i$-vei
nyina.
NMLZ:F-DEM:DIST PFV-weave.STR mat

'The woman is weaving a mat, is mat-weaving.'

b. Nyibä enge i-vili-no.

basket DEM:PROX PFV-weave.TR-1MIN.A

'I wove this basket.'
a. I-ki-gou
nenu.
1MIN.S-IPFV-husk.STR coconut
'I am husking coconuts.'
b. Nenu enge i-gu-no.
coconut DEM:PROX PFV-husk.TR-1MIN.A
'I husked these coconuts.'

Thirdly, nuclear-layer verb serialisation - the use of multiple verb roots within a single inflected form - is extremely frequent in Äiwoo, and comes in two main types. In the first, which I call manner serialisation, the initial verb describes an event, and any following forms modify this verb. In this construction, the transitivity of the whole form depends on the transitivity of the initial verb; an intransitive verb modifying a transitive one will be followed by the suffix - $i$ or -nyi, glossed 'transitive', and the whole construction takes transitive person marking (5b). Note that aspect prefixes, aspect enclitics and person markers apply to the entire complex form.

a. Ki-lo lopâ-päko-mana $=$ to.

IPFV-RED $\sim$ speak-good-very $=\mathrm{PH}$

'(The child) could speak very well.'

3. E.g. vei-vili 'weave', kei-kili 'dig', lei-li 'grate'; gou-gu 'husk', tou-tu 'carry', bâkou-bâku 'fold'; lâwâa -lâa 'build', eâwââ-eâa 'pull', gâwââ-gââ 'count'. 
b. I-malei-päko-i-du-gu-i.

PFV-care.for-good-TR-all-3MIN.A-3AUG.O

'She looked after all of them properly.'

(Lo)lopâ 'speak', malei 'take care of, look after' and päko 'be good' all occur as independent verbs in Äiwoo. mana 'very', on the other hand, does not, and is probably more appropriately characterised as an adverb, which might here be said to be incorporated into the verb complex. The line between verbs and adverbs in this type of complex construction is not, however, always easy to draw. For example, an item may be far more frequent as a modifier in a complex construction than as an independent verb, while still allowing a verbal use; and the same structural position may be able to accommodate both clearly verbal and clearly adverbial items (cf. also Margetts 2005, Pawley 2003).

In the second type of serialisation construction, which is most relevant for the present purposes, the verbs in the series each describe distinct aspects of a single event. I call such constructions complex-event serialisations. Complexevent serialisations differ from manner serialisations in that their transitivity depends on the transitivity of the final verb, which usually describes the effect of the act denoted by the initial verb. Thus there is no overt transitive suffix of the type found in manner serialisation.

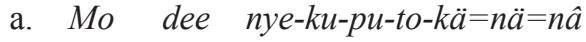
CONJ this NMLZ:LOC-IPFV-come-go.in-DIR:3=OBL.PRO=DEIC:DIST
lâ $\quad i$-so-bengi $=n \hat{a}$.
DEIC:DIST PFV-stand-block=DEIC:DIST
'Because he was blocking the way she had come.'
b. I-wo-pongi mo ba i-liaa-kä=gu.
PFV-go-chase CONJ NEG PFV-reach-DIR:3=NEG
'He chased him but didn't reach/catch him.'

so 'stand' and wo 'go' are intransitive verbs, but the structures as a whole are transitive, since bengi 'block' and pongi 'chase' are transitive verbs. Complexevent structures like those illustrated (6) may in turn be modified by a serialised verb or adverb, creating in effect a combination of the two serialisation types, where the complex event description effected by the first two verbs is in turn modified by another verb (7):

(7) I-lo lo-bâku-päko-i-kä.

PFV-RED hold-fold-good-TR-DIR:3

'She folded them properly.'

lo-bâku 'hold-fold' is the usual expression for an act of folding something, but both elements also occur independently as verbs, and so this must be considered an instance of a complex-event serialisation. This complex structure is in 
turn modified by päko 'be good' in a manner serialisation construction. The possibility of combining different types of serialisation may indicate that a description of complex verb forms in terms of positional slots, similar to that proposed for Saliba by Margetts (2005), could also be appropriate for Äiwoo. Under such an analysis, the first and second slots of a complex construction are filled by verbs describing a cause and its effect, while the third - and any subsequent - slots host various kinds of manner modifiers. The difference between the constructions illustrated in (5-7) would be that in (5), only the first and the third slots are filled, whereas (6) fills the first and second slots, and (7) fills all three. However, the problem of determining the formal status of some of the forms found in these slots, as exemplified by the description of cut and break verbs below, may complicate such an analysis.

\subsection{The verbal lexicon}

Äiwoo verbs can be complex in more than one respect. As noted above, serialisation of otherwise independent verbs roots is common; but the verbal lexicon also contains numerous items which are clearly segmentable, but where the individual segments do not necessarily have an independent use.

Take example (7) above, where the form lobâku was glossed as consisting of lo 'hold' and bâku 'fold'. In this case, both morphemes are attested either as independent verb roots (bâku), or in other complex forms where a consistent semantic content of the individual segments can be identified (lo). However, there are numerous examples of less clear cases. Other attested forms composed of $l o$ 'hold' plus a second element include, for example, lokei 'turn over a pig by grabbing it by the leg', lolope 'untangle', and lolou 'rummage inside something'; but kei, lope and lou are not attested as independent verbs, ${ }^{4}$ nor do they occur in other complex forms with a consistent identifiable meaning. Similarly, in the forms ngäbe 'pound with a pestle', ngänyi 'plant, push into the ground', ngävilei 'poke holes in a pudding to allow coconut cream to seep through', the initial element ngä may be hypothesised to share a meaning along the lines of 'downward thrusting motion'. But this element is not attested with an independent use, and no clear parallels to the final elements -nyi and -vilei have been identified in other forms (for -be, see Table 3 below).

It is clear, then, that the Äiwoo verbal lexicon contains forms that have undergone varying degrees of lexicalisation from original serialised verbs. In general, such forms appear to be of relatively low productivity - that is, the complex forms are lexicalised as wholes, and although speakers may in some cases offer meanings for individual parts, these parts are not used in an un-

4. There is a verb $k e i$ ' dig', but it is not clear what the semantic link would be with lokei; possibly the "turn over" meaning might be considered to link the two. 
restricted way to productively construct new forms. It should be emphasised, however, that more research is needed into the structure of the verbal lexicon and the productivity of complex verbal forms in Äiwoo.

\section{3. "Cut and break" forms}

\subsection{Structural properties}

Despite the general low productivity of combinations of verbal segments as discussed above, it is clear that there is more productivity in some parts of the verbal lexicon than others. Specifically, this concerns the forms used to describe cut and break-type events, that is, volitional directed acts carried out by an agent with the intention of bringing about a change of state in an object. In Äiwoo, such forms are systematically constructed out of two parts. The first element refers to the act which is carried out in order to bring about the destruction of the object, and the instrument used, if any; the second element refers to the way in which the object breaks (snapping, smashing, cracking open, being squashed, etc.). Such complex forms consisting of two bound elements with clear independent meanings I will refer to as "cut and break forms" or "C\&B forms".

(8) a. tä + ki

Nyenaa i-tä-ki-no.

tree PFV-cut-break.rigid.obj-1MIN.A

'I cut the stick (with a knife).'

b. tä + lu

Nuwale $i$-tâ-lu-kä=nâ.

rope $\quad$ PFV-cut-break.flexible.obj-DIR:3=DEIC:DIST

'He cut the rope.'

c. tä + pule

Sapolo ki-tâ-pule-no.

papaya IPFV-cut-break.in.half-1MIN.A

'I cut open the papaya.'

d. $\quad$ tä $+\mathrm{ji}$

Onion nugo ki-tä-ji-woli-no.

onion POSS:FOOD.1MIN IPFV-cut-small.pieces-go.down-1MIN.A

'I chop up my onion.'

(9) a. lä + ki

Nyenaa i-lä-ki-no.

tree PFV-chop-break.rigid.obj-1MIN.A

'I chopped down the tree.' 
b. $\quad$ lä $+\mathrm{lu}$

Nuwale $i$-lâ-lu-kä=nâ.

rope PFV-chop-break.flexible.obj-DIR:3=DEIC:DIST

'He chopped off the rope'

c. lä + gäsi

Näte enge lä-gäsi-woli.

firewood DEM:PROX chop-cleave-go.down

'Split this firewood.'

(10)

a. to $+\mathrm{ki}$

Nyenaa i-to-ki-no.

tree PFV-strike-break.rigid.obj-1MIN.A

'I chopped down the tree.'

b. to + bi

Tin i-to-bi-no.

tin PFV-strike-crumple-1MIN.A

'I bent the tin out of shape by striking it.'

The C\&B forms are highly similar to the cause-effect serialisations described in 2.3 above, with one important distinction: the elements involved do not have an independent use. The forms $t \ddot{a}-\mid t \hat{a}-$ 'cut (with sawing motion, using a knife)', lä-/lâ-5 'chop', to- 'strike, punch', -ki 'break, snap (of rigid objects such as wood), -lu 'break (of long flexible objects such as rope)', -pule 'break open, break in half', $-j i$ 'be cut into small pieces', -gäsi 'cleave', - $b i$ 'crumple' do not occur outside of cut and break constructions and are never cited independently by speakers as individual forms with independent meanings. Most of the forms found in such constructions are monosyllabic, though examples of disyllabic forms can be found, as seen in (8c) and (9c) above.

Äiwoo shows a large range of such bound elements used both in the first and the second slot of C\&B forms. In principle, they may be productively combined, although combinations describing physically impossible or highly unlikely events are usually judged unacceptable. I include in the discussion only forms whose individual parts have clearly identifiable meanings and may be productively combined, and consider these to be the characteristic properties of C\&B forms. It should be noted, however, that the line between such forms and the lexicalised-but-complex forms described in 2.4 above is probably not a sharp one. An indication that the C\&B forms nevertheless form a fairly coherent class may be that speakers volunteering to "explain the system" (in response to the researcher's attempts to understand why, for example, one would say täki

5. The variation between the forms in $-\ddot{a}[æ]$ and $-\hat{a}[a](t \ddot{a}-/ t \hat{a}-, l \ddot{a}-/ l \hat{a}-)$ is conditioned by the vowel in the following syllable. 
for cutting a stick but $t a ̂ b u$ for cutting a piece of cake) clearly treated "cutting and breaking acts" as a coherent domain, both in a practical demonstration initiated by a group of speakers of types of acts and the forms used to describe them, and in a list of relevant forms volunteered by one speaker.

Some examples of individual morphemes found in C\&B forms are listed in Table 3; the list is not exhaustive (see also Næss and Boerger 2008: 201-2).

Table 3. Examples of elements found in Äiwoo cut \& break forms

\begin{tabular}{|c|c|c|c|}
\hline $\begin{array}{l}\text { Initial } \\
\text { (cause) } \\
\text { element }\end{array}$ & Meaning & $\begin{array}{l}\text { Final } \\
\text { (effect) } \\
\text { element }\end{array}$ & Meaning \\
\hline$b a-$ & $\begin{array}{l}\text { hold both ends and push; } \\
\text { 'prototypical' breaking }\end{array}$ & $-b e$ & become soft as result of impact \\
\hline$b u$ - & push with sole of foot & $-b i$ & crumple, bend out of shape \\
\hline$e \ddot{a}-$ & slice, cut into small pieces & $-b u$ & break, of soft crumbly objects \\
\hline lâ-|lä- & chop & -gäsi & cleave \\
\hline$n u-$ & pinch, squeeze between fingers & -gulo & crack open \\
\hline po- & kick & $-k i$ & break, snap, of long rigid objects \\
\hline$t \hat{a}-\mid t \ddot{a}-$ & cut with sawing motion & $-l u$ & break, snap, of long flexible objects \\
\hline to- & strike with a single hard punch & -ngii & smash, shatter \\
\hline$v \ddot{a}-$ & hit with a long instrument & $-s i$ & be chipped \\
\hline wo- & tap, hammer & -täli & tear, rip apart \\
\hline
\end{tabular}

The use of such complex forms is clearly the norm when referring to acts of targeted destruction or modification of an object. The only case of a possibly monomorphemic form being used in the descriptions of cut and break events in the "Kids' Cut and Break" film clips is uuku 'file, rub with a sawing motion' used by one speaker to describe a clip where a man uses the blade of an axe in a sawing motion to cut a branch off a tree; this verb is in a serialisation construction with $l \hat{a}$ ' $g o$ out' describing what happens to the branch as a result (it "goes out" from the tree trunk):

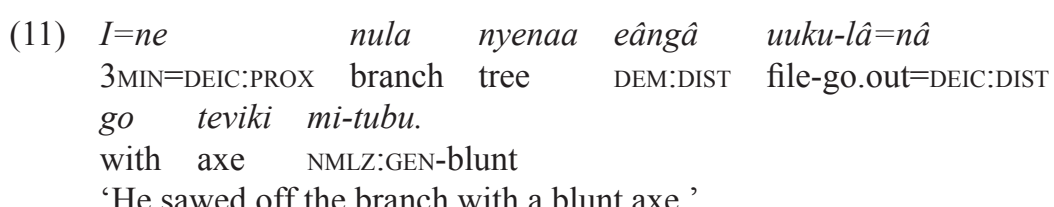

In addition, one other description does not use a complex cut and break form but rather an applicativised form of the intransitive verb vetängä 'destroy (things), be destructive' to describe a man smashing a flowerpot; the rest of the descriptions have complex cut and break forms of the type described above. 


\subsection{Semantic distinctions}

It should be clear from the outline presented above that the Äiwoo system of C\&B forms allows for very detailed semantic distinctions. A large range of actions can be specified both in terms of the particulars of the act carried out - with a knife, an axe, a long instrument, the hand; chopping, slicing, pinching, grasping, striking, punching, and so on-and of the exact effect achieved on the object. The latter to a large extent depends on the nature of the object, in particular its shape and the material of which it consists, since different objects break in different ways.

The system allows for different descriptions of the same event, at different levels of generality or focusing on different aspects of the event. For instance, the difference between läki and toki 'chop', illustrated in (9a) and (10a) above, was explained as relating to the force used; toki is used when the act of chopping requires hard blows, and would typically be used for larger trees, while läki is appropriate for smaller trees or sticks. Thus it is not the tool used or the effect achieved that distinguishes the two; rather to- 'strike, punch' focuses on the nature of the act as involving hard blows, while $l \ddot{a}$ - refers to chopping in general.

For the description of film clip 18, where a person breaks a piece off a bread roll, one speaker chose the form $n u$-bu 'pinch-break.crumbly.object', focusing on the fact that the actor pinches a piece of bread between his fingers to break it off, while another chose the more general form babonge, where $b a$ - is the most general 'break' form appropriate for any act of seizing an object in one's hand to break it (-bonge is the semi-transitive form of - $b u$, cf. 3.3 below). The choice to focus on the manner in which the action is carried out in (12a) is further emphasised by the addition of the prepositional phrase go nyimä 'with his hand', as well as the semantically generic object 'food' (literally a nominalised possessive form meaning, roughly, 'His thing for him to eat'), whereas the speaker in (12b) specifies that what is going on is the breaking of bread.
a. $\quad I=n \hat{a}$
de-na $=n \hat{a}$
$3 \mathrm{MIN}=$ DEIC:DIST
NMLZ:THING-POSS:FOOD.3MIN= DEIC:DIST
$i-n u-b u$
go nyimä
PFV-pinch-break.crumbly.obj.TR with hand.3MIN
'He broke his food with his hand.'
b. Sime nyigi ku-ba-bonge
bred.
person one IPFV-grasp-break.crumbly.obj.STR bread
'A person broke some bread.'

Presumably, some of the forms made available through this system may be seen as more specialised instances of other forms; the initial element $b a$ - seems to be general enough in meaning to be appropriate for most acts of breaking 
carried out with the hands, whereas if an instrument is used this normally has to be specified. Even with the extremely detailed semantic distinctions made available by the system, then, the description of any given cut and break event is not fully predetermined; rather, the speaker chooses a construal of the event to be described which focuses on certain aspects of the causing and resulting events. In some cases only one such construal may be readily available, while other events may allow for alternative perspectives.

\subsection{Formal properties}

Historically, the C\&B forms almost certainly originate in serialisation constructions of the type described in 2.3. It is not unusual for cutting and breakingtype events to be described by serialising constructions in other Oceanic languages, for instance in Saliba (Papuan Tip), where serialisation is the normal way to refer to such events (Margetts 2005). Further evidence for a verbal origin is the fact that at least some of the elements found in second position of a $\mathrm{C} \& \mathrm{~B}$ form show the transitive/semi-transitive alternation, as illustrated by (13-14):
a. Nyenaa-ee i-lä-ki-no.
tree-DEM:PROX PFV-chop-break.rigid.obj.TR-1MIN.A 'I chopped down this tree.'
b. Me-ki-lä-ke näte.
1AUG.S-IPFV-chop-break.rigid.obj.STR firewood
'We chopped firewood.'
(14) a. Nyigââ eângâ wo-gulo.
sea.almond DEM:DIST tap-crack.open.TR
'He cracked that sea almond open.'
b. Мi-nâ-wo-go пепи.
2MIN.S-IRR-tap-crack.open.STR coconut

'Go and break open some coconuts.'

There are, however, a number of differences between $\mathrm{C} \& \mathrm{~B}$ forms and serialised verbs. Firstly, by definition, the elements participating in a serial verb construction have independent uses as lexical verbs; the elements of a $\mathrm{C} \& \mathrm{~B}$ form have no such independent uses, and cannot be cited individually.

Secondly, a serial verb construction in Äiwoo, though a single grammatical word in the sense that it takes a single set of grammatical affixes and clitics, nevertheless constitutes multiple phonological words. Each component verb stem is pronounced with a distinct main stress, and indeed Äiwoo speakers tend to be critical of having such forms written as a single orthographic word; they claim that "we don't have such long words in our language". In the intuition of Äiwoo speakers, then, phonological criteria would seem to override 
grammatical criteria with respect to the question of wordhood; multiple phonological words are perceived as multiple words even when they make up a single grammatical word.

C\&B forms, by contrast, are single phonological words with no possibility of individual stress on the component elements. They follow the usual pattern of stress assignment for lexical words in Äiwoo, with main stress assigned to the penultimate syllable of the word, unless this syllable has a high vowel ( $i$ or $u$ ). In the latter case, the vowel is devoiced or elided and stress shifts to the preceding syllable. Thus the stress patterns of forms like 'täki 'cut', lä'gäsi 'cleave', ba'bonge 'break' are indistinguishable from those found in monomorphemic lexical words.

Furthermore, while a serial verb construction may consist of more than two verbs in serialisation - forms with three serialised verbs are common, though more than three seems to be fairly rare - the C\&B forms may only consist of two bound stems, one from the "cause" set and one from the "effect" set. It is possible to further serialise one or more verbs to a $\mathrm{C} \& \mathrm{~B}$ form - in other words, the $\mathrm{C} \& \mathrm{~B}$ forms act as verbs for the purposes of serialisation - but we do not find more than two bound roots in a C\&B form.

From the available data it does not appear to be possible to interpose material between the two verb stems of a cause-effect serialisation, though this has so far not been explicitly tested. It is certainly the case that no material may intervene between the two elements of a C\&B form. Consider an example like (15), with the form pängii 'throw-smash', where $p \ddot{a}$ - is clearly related to the independent verb päi 'throw' (cf. 3.4 below). A directional verb such as woli 'go down' used to modify such a form notionally modifies only the first part; it is the throwing, not the smashing, that is carried out in a downward direction. Nevertheless, it is not possible as an alternative to (15) to have woli directly following $p \ddot{a}$-; a form like *päwolingii is impossible.

$\begin{array}{lll}\text { I-siwo-ee } \quad \text { pleti=kâ } & \text { mo } \quad l \hat{a} \\ \text { PFV-hold-go.up plate= DEIC:DIST } & \text { CONJ } \quad \text { DEIC:DIST } \\ \text { wo-pä-ngii-woli-kä } & \text { ngä } & \text { tebol=kâ. } \\ \text { go-throw-smash-go.down-DIR:3 } & \text { LOC } & \text { table=DEIC:DIST }\end{array}$

'She held the plate up and threw it down on the table, smashing it.'

The scope of grammatical morphemes such as aspect marking, person marking or negation is always over the whole complex form; however, these criteria cannot be employed to distinguish single words from serialised forms, since they apply to serialisations in general, cf. 2.3 above.

Both grammatically and phonologically, then, C\&B forms fulfill the criteria for wordhood in Äiwoo. The fact that the elements making up a complex C\&B stem normally do not have an independent use further indicates that the $\mathrm{C} \& \mathrm{~B}$ 
forms should in fact be understood as single words. The latter criterion, however, is not without exceptions.

\subsection{Independent verbs in $C \& B$ forms}

While the elements of $\mathrm{C} \& \mathrm{~B}$ forms are, as a rule, not attested as independent lexical items, there are a few independent verbs which may enter into the construction. Most frequently, the independent verb occurs in the initial position, combining with a bound morpheme specifying the effect of the verbal action. Attested examples include soki 'stand on something rigid and break it' (so 'stand'), koki 'lie on something rigid and break it' ( $k o$ 'lie'), eââlu 'pull at something flexible and break it' (eâa 'pull'). In other cases the element found in this position is clearly a phonetically reduced form of an independent verb, e.g. mâa 'bite, grip between teeth', maki 'bite off something rigid', mabe 'chew on something to soften it'; päi 'throw', pägulo 'throw something at an object and crack it open', päsii 'throw something at an object and rip a hole in it'.

The possibility of inserting independent verbs into one of the slots of the construction further complicates the question of the status of C\&B forms as words or sequences of independent stems. The situation parallels to some extent that found in certain North American languages such as Klamath, where so-called bipartite stems may be made up of two elements with distinct lexical meanings but no independent use, or of one such bound element plus an independent verb (DeLancey 1999). In the first type of case, DeLancey notes that "there is no obvious way to identify one of the morphemes as the verbal root and the other as a derivational element: neither can occur alone as a verb stem" (DeLancey 1999: 60); in Klamath, the majority of verb stems appear to be of this type. Like in Äiwoo, the second element of such bipartite stems shows verbal properties, such as reduplication and irregular stem alternations (DeLancey 1999: 63). Though not addressing the status of bipartite stems with respect to formal criteria of wordhood, DeLancey notes that "bipartite stems are lexical items" in the sense that their semantics may not be completely predictable from the meanings of their parts (1999: 75); and the terminology "Lexical Prefixes" (LPs) for the initial elements and "Locative-Directive Suffixes" (LDSs) for the final elements further suggests that the "prefixes" and "suffixes" together make up a single word. DeLancey further notes that though the modern Klamath system of LPs and LDSs has several distinct diachronic sources, one major source must have been a verb compounding construction combining two independent verb stems (DeLancey 1999: 79-80).

Äiwoo C\&B forms, then, consist of two elements which, in the typical case, are historically verbal but synchronically bound, being found only in this particular type of complex stem. In this they may also be said to resemble what has been called "combining forms" in English, i.e. forms such as geo-graphy 
or demo-crat which consist of bound forms with lexical meanings. The term is usually applied only to bound stems of Greek and Latin origins in English (see Warren 1990 for a thorough discussion of the term), though Haspelmath (2002: 21-22), referring to a set of examples from the Salishan language Bella Coola, suggests that it would also be appropriate for forms similar to those discussed for Klamath above.

Crucially, however, the Äiwoo construction also allows for the use of certain synchronic verbs in one of the slots and a bound form in the other; if synchronic verbs appear in both slots, we have a serial verb construction. There is, then, a graded series of progressively more integrated forms in the Äiwoo inventory of cause-effect constructions.

\section{Words, complex words and serialisations: A cline of event integration}

According to Koptjevskaja-Tamm et al. (2007: 160-162), one of the "focal questions for lexical typology" is the following: "What meanings can or cannot be expressed by a single word in different languages?" Naturally, the answer to this question depends crucially on what is taken to constitute a "single word". Indeed, it is not clear to what extent "word" is a valid crosslinguistic concept, in the sense that criteria for wordhood vary between languages (Dixon and Aikhenvald 2002). As a result, what kinds of concepts may be expressed in a given language by a "single word" depends not only on conceptualisation patterns within the language community in question, but also on which criteria can be applied in a given language to identify the unit "word".

The fact that there are no crosslinguistically valid criteria for identifying "words" does not, however, mean that comparing "words" between languages is a meaningless exercise. ${ }^{6}$ The question of which kinds of concepts may be encoded in a cohesive, independent unit of language is clearly interesting from a cognitive linguistic perspective even though the precise formal nature of such units may vary across languages. In the present context, the fact that the units under discussion vary in cohesion and independence within a single language seems to me further evidence for the relevance of the concept of "word", in that we may study the correlation between the degree of "wordiness" of a unit and the conceptual integration of the event that the unit is used to describe.

As has already been noted, the verbal lexicon in Äiwoo contains forms at various degrees of lexicalisation. This includes the forms used to describe cut and break-type events, which may be seen as ranging along a cline from single

6. As suggested by an anonymous reviewer, who proposed that it might be more fruitful to compare "morphs". But morphs are of different types too-for instance, roots, affixes, cliticsand it is not clear to me that examining which kinds of meaning may be expressed by a single "morph" across languages would necessarily yield more interesting or meaningful results. 
words at one end to serialised verbs at the other. What has been described above as " $\mathrm{C} \& \mathrm{~B}$ forms" clearly function as single words, even though they are internally complex; their constituent elements do not have status as independent words, they cannot occur outside the $\mathrm{C} \& \mathrm{~B}$ constructions, and the complex forms fulfill all grammatical and phonological criteria for wordhood. Further along the cline we find forms where one of the elements does have status as an independent word, while the other does not; and finally we have constructions where two independent verbs are bound together in a serial verb construction.

The choice between these different types of construction to describe an event of someone acting to bring about an effect in an object is far from random. The relevant semantic parameter appears to be whether the constituent subevents - the causing event and the resulting change of state in the objectare perceived as being able to occur independently or not. "True" C\&B forms in Äiwoo are used when two conditions hold: the change of state described is understood as not normally coming about without a causing subevent (though see 5.2 below on inchoative forms), and the causing act is construed as being directed towards a goal and, consequently, as not occurring without giving rise to some effect. Crucially, even if such an act is performed without giving rise to the expected result, whether deliberately or by accident, a complex form is still used, with a "result" component indicating the appropriate (lack of) outcome, e.g. toji 'strike at something and miss or just graze it', towaаmu 'pretend to strike', tokai 'strike at something to scare it away (not necessarily making impact)'. That is, at least in the semantic domain of cut and break-type events, inherently goal-directed acts require a specification of their result, even if that result is not that intended or conventionally associated with the act in question. There is no term for 'hit' which is strictly speaking neutral as to its effect, though to-gulo 'strike-crack.open' is conventionalised as a general 'hit' verb; it is used e.g. to refer to people hitting each other, with no implication that the affected body part actually cracks open. The point is that the alternative strategy of simply leaving the effect unspecified is unavailable; to- 'strike' —or any of the other forms listed in Table 3 above, along with many others not mentioned here - cannot be used except in combination with a form specifying the result of the act.

There are acts which are construed as independently occurring, in that they are not inherently goal-directed, but which may nevertheless be carried out in a goal-directed manner so as to achieve a certain result. These are the cases where an independent verb may be used in a $\mathrm{C} \& \mathrm{~B}$ construction in combination with a bound form: $s o$ 'stand' describes an action not typically directed towards a goal or associated with an effect, but which can be carried out as a means to achieve some effect, as in soki 'stand on (a stick) to break it'.

Finally, there are events which may occur independently of a cause, but which can also be brought about through some causal act. When describing 


\section{A. Noess}

a caused event where both cause and effect might in other cases occur independently - that is, the "cause" act need not necessarily imply an effect, and the "effect" act could come about without a directed act of causation-a serial verb construction is used. Blocking something, for example, is not necessarily the result of a goal-directed act - a tree or a rock can block a road or an entrance without being perceived as being the result of a causing event. But it can be construed as coming about as the result of a causal act, as in so-bengi 'stand-block' in example (6a).

The cline of structural integration in Äiwoo cause-effect expressions can thus be seen to reflect a cline of event integration. The formal description of a causal event depends on the perceived integration of the cause and effect subevents: if these subevents are so tightly integrated that they do not occur independently, a $\mathrm{C} \& \mathrm{~B}$ form is used; if they might equally well occur independently of each other, serialisation of independent verbs is used. In between there is the possibility of combining an independent verb with a bound C\&B element, if one subevent may be construed as potentially independent while the other may not.

Consequently, the question of which meanings can be expressed by single words may be answered for Äiwoo as follows: a single word may express any event the subevents of which are perceived as not normally occurring independently: goal-directed acts carried out to bring about an effect, and effects which do not arise independently of such acts. Äiwoo is unusual, however, in that it allows for-indeed, requires - the expression of both aspects of such acts in what must be described as a single word; both cause and effect must usually be specified. The exception is the inchoative forms, to which we now turn.

\section{Inchoative forms}

\subsection{Previous accounts}

Guerssel et al. (1985) examine cut and break verbs in four unrelated languages - English, Berber, Warlpiri and Hocãk (Winnebago) - and find that there is, in general, a distinction between verbs of cutting and verbs of breaking, such that "cut" verbs can participate in the conative but not the inchoative alternation, whereas "break" verbs can participate in the inchoative but not the conative alternation. As an example, in English it is possible to say He cut the bread or He cut at the bread, but not *The bread cut, whereas one can say He broke the glass or The glass broke, but not *He broke at the glass. Guerssel et al. explain this pattern by an analysis of lexical-conceptual structure where break verbs have a monadic representation, specifying only the participant undergoing the change, but may be causativised by a productive lexical rule; this option 
is, however, not available to cut verbs, for which the lexical-conceptual structure has two participants from the outset.

Bohnemeyer (2007) points out that this analysis hinges on the assumption that the inchoative sense of break verbs is basic, which is not uncontroversial. He proposes instead an alternative account based on two principles labelled "Morpholexical Transparency" and "Complete Linking":

Morpholexical Transparency: productive A[rgument]-structure alternations that relate two lexemes in a semantically transparent fashion can add or delete generic, but not specific, subevent representations from the event structure of the verb.

Complete Linking: a well-formed syntactic projection from a verb lexeme requires all thematic relations spelled out in the verb's semantics to be linked to arguments or obliques specified in the verb's A-structure, unless they are blocked from linking by voice operations. (Bohnemeyer 2007: 158)

Generic subevent representations are those which simply specify the presence of a subevent and its role, e.g. "cause" and "state change" in the domain of C\&B verbs. Specific representations further elaborate on the details of the nature of these subevents: the manner in which a change is brought about, the instrument used, the degree or type of affectedness of the object, etc. The latter type of information "is inherently lexical and therefore cannot be added or erased by transparent morpholexical processes or alternations" (Bohnemeyer 2007: 158). In other words, the reason why break verbs but not cut verbs can have inchoative forms is that the causal subevent of a break verb is semantically generic, and can therefore be removed by an $\mathrm{A}$ (rgument)-structure alternation; while cut verbs specify some property of the instrument or the way it is used, information which cannot be suppressed through an A-structure alternation.

\subsection{Bipolar verbs and the Äiwoo inchoative construction}

Bohnemeyer further notes that there is a group of languages which does not conform to the pattern of argument structure alternations predicted to hold for break and cut verbs, respectively. These are languages in which $C \& B$ verbs are "bipolar"; that is, they make explicit reference both to the causing event and its effect on the object within a single construction. This can be achieved, for example, through verb serialisation, as in Mandarin (Chen 2007), compound verbs, as in Yukatek (Bohnemeyer 2007: 164), or constructions consisting of a verbal root plus a dependent element or particle, as in German, exemplified by the verb pair schmettern 'smash' vs. zer-schmettern 'smash to pieces' (Bohnemeyer 2007: 163). Since such bipolar verbs are semantically specific regarding both the nature of the cause and the nature of the effect, neither subevent may be removed through an argument structure alternation. An inchoative 


\section{A. Noess}

derivation, then, which in Bohnemeyer's definition "remov[es] the causal subevent from the base's meaning" (Bohnemeyer 2007: 165) should not be possible with a bipolar verb.

Äiwoo C\&B forms clearly fall under the definition of bipolar verbs, and so by Bohnemeyer's account should not allow inchoative forms. In fact, inchoatives can be productively formed from, in principle, any $\mathrm{C} \& \mathrm{~B}$ forms in Äiwoo, and so it may seem as if this language violates not only Bohnemeyer's but also Guerssel et al.'s generalisation. In fact, however, Äiwoo does not so much violate these generalisations as provide a way around them. Inchoative forms of Äiwoo C\&B verbs are formed with the prefix bo-, which specifies that the object undergoes the effect denoted by the second element of the C\&B verb, while leaving open the question of whether or not an external cause is present. The bo- forms are formally intransitive and are most frequentlythough not always - formed with the semi-transitive variant of the second-slot morpheme, where such a variant exists.

Crucially, however, this inchoative morpheme does not attach to the whole complex C\&B form; rather, it replaces the initial element. That is, the causal part of the complex structure is "removed from the meaning" simply by removing the causal morpheme. But since the effect part of the verb cannot occur on its own, the causal part cannot simply be omitted, but must be replaced by something else - the form bo. This is further evidence that the Äiwoo C\&B forms are not serialised verbs, but have an internal structural integrity which requires both formal elements to be present, even if only one of them is semantically required. This is clearly different from the serialising structure in Mandarin, where "result verbs" occurring in complex C\&B constructions may be used on their own with an inchoative meaning (Chen 2007: 281). The relationship between transitive C\&B forms and their inchoative counterparts in Äiwoo is probably best thought of as derivational, in that one bound morpheme alternates with another; an equipollent alternation in the terminology of Haspelmath (1993).

The bo- forms have both stative (16a) and inchoative (16b) uses:

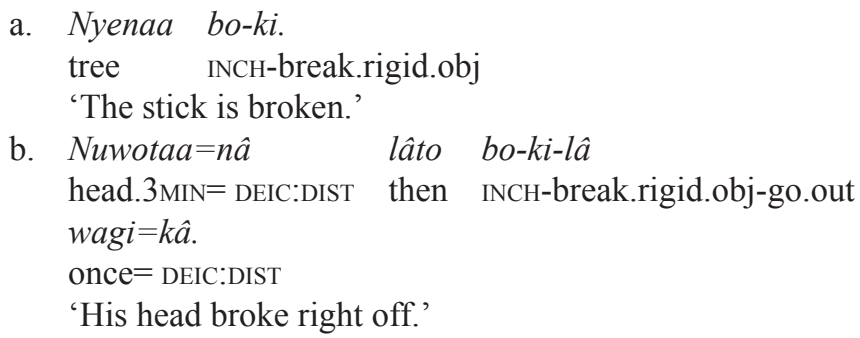

boki in example (16b) refers to a spontaneously occurring event; the man in question has had his insides eaten away by a centipede, so his body is brittle, 
and his head breaks off when he shakes the water off after a bath. However, it is also possible to use the $b o$ - forms to refer to events which do have an external cause. Examples $(17 \mathrm{a}-\mathrm{b})$ show that a bo- form and a regular $\mathrm{C} \& \mathrm{~B}$ form may be used to refer to the same event. They were elicited by means of a video stimulus set called "Staged Events" (van Staden et al. 2001). The purpose of this stimulus is to establish which types of event descriptions may be referred to by single verbs vs. complex constructions in different languages. It consists of short video clips with people acting out various scenes; after the speaker has described a few clips, a still is shown taken from each of the clips just seen, and the speaker is asked to describe what s/he saw in the clip from which the still is taken. Example a. is from the description of a film clip where a woman drops a hammer onto a plate, smashing it, while $b$. was prompted by a still from the same clip.

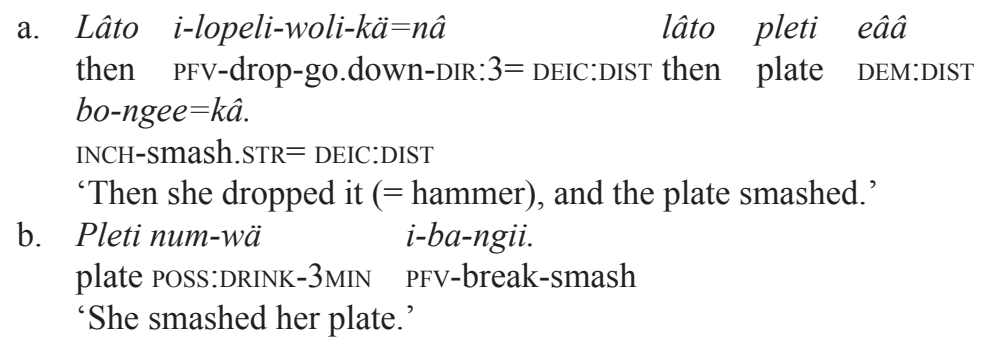

This pattern resembles that described for break verbs in Warlpiri and Hocãk in Guerssel et al. (1985: 56), where the causative and the inchoative forms are derivationally related rather than being identical forms used in different syntactic frames. However, in neither of these languages do cut verbs enter into the alternation (Bohnemeyer 2007: 156). By contrast, in Äiwoo it is impossible to draw a distinction between the behaviour of "cutting" and "breaking" verbs in the causative-inchoative alternation, because the distinction is simply neutralised in the inchoative construction. I did not explicitly test to what extent the $b o$ - forms are actually used to describe cut-type events, but is certainly possible to use the construction to describe effects which are commonly achieved by cut-type verbs, e.g. bokäsi 'cleave, be cloven'. But since the distinction between "cutting" and "breaking" events depends to a large extent on the initial morpheme of a complex form, and this morpheme cannot be present in the inchoative form, an inchoative cannot be categorised as either a "cut" verb or a "break" verb.

\subsection{Is the Äiwoo inchoative an argument-structure alternation?}

Bohnemeyer's definition of an A[rgument]-structure alternation includes, in addition to polysemous verbs with different argument-structure properties, 


\section{A. Noess}

"morpholexical operations ... that transparently change a verb's thematic structure and subcategorisation" (2007: 154). We have seen that, while Äiwoo inchoatives in bo- are compatible with the presence of an external cause, they do not require it; (16b) above illustrated the use of a bo-form to refer to a spontaneously occurring event. Haspelmath (1993: 90) notes that, though an inchoative form presents a situation as occurring spontaneously, this does not mean that there cannot be an agent present in the objective situation; for instance, The snowwoman melted and The sun melted the snowwoman may be used to refer to the same objective situation. The Äiwoo inchoative thus seems to fulfill the criterion of changing a verb's argument structure; it removes the causing agent from the argument structure and presents the event as occurring spontaneously.

Whether these forms conform to Bohnemeyer's definition of an argumentstructure alternation is therefore a question of whether the $\mathrm{C} \& \mathrm{~B}$ forms are "verbs" that have their thematic structure changed through the replacement of their initial morpheme with inchoative bo-. Given the indisputable status of the C\&B forms as phonological and grammatical words, as discussed in 3.3 above, I see no reason not to assign them the status of verbs - indeed, I do not see what other status they could be given. This means that Äiwoo appears to violate Bohnemeyer's principle of Morpholexical Transparency cited above: if the inchoative $b o$ - construction is an argument structure alternation, it clearly "deletes a specific subevent representation" from the argument structure of the verb. It should be noted, of course, that this alternation only applies to a specific subclass of Äiwoo verbs, namely those consisting of two bound morphemes indicating a causing subevent and an effect subevent, respectively. Bohnemeyer, however, explicitly states that "bipolar verbs are inert regarding A-structure alternations: since both the causal and the resulting subevent representations are specific, neither can be removed from the meaning of a transparently related stem" (2007: 163); this clearly does not hold for Äiwoo C\&B forms.

At the same time, the fact that an Äiwoo C\&B verb consists of two bound roots complicates the question of what counts as an "alternation". The fact that in the inchoative part of the verb stem is removed might be seen as an indication that the inchoative in Äiwoo does not simply change the verb's "thematic structure and subcategorisation", but changes the verb itself, and that this goes beyond the definition of "argument structure alternation" in spirit if not in letter. I do not believe that there is anything to be gained by insisting that the facts in Äiwoo either do or do not "violate" the generalisations discussed above; the essential point is rather that cut and break verbs in Äiwoo exhibit a pattern not previously attested, which throws a new light both on the generalisations previously formulated and on our understanding of the crosslinguistic nature of cut and break verbs in general. 
On the other hand, Äiwoo does confirm the claim that "[b]ipolar verbs make a bipartition of the $\mathrm{C} \& \mathrm{~B}$ domain in cut and break $\mathrm{A}$-structure classes impossible in those languages in which they occur" (Bohnemeyer 2007: 165). It does so, however, in an unexpected manner: not by disallowing argument structure alternations altogether, but by having an inchoative derivation which neutralises the distinction between cut and break verbs. Thus, while C\&B forms in Äiwoo can be semantically classified into those referring to cut-type events and those referring to break-type events, they do not differ in their ability to participate in argument structure alternations. The lack of a formal bipartition into cut-type and break-type classes thus holds even for intransitive $\mathrm{C} \& \mathrm{~B}$ verbs in Äiwoo.

\section{Conclusion}

Äiwoo provides several insights into the ways in which events of targeted destruction may be lexicalised in language, and how the semantic structure of event expressions interacts with argument-structure alternations.

Firstly, it shows that the perceived degree of event integration may be directly reflected in the degree of morphosyntactic integration of the expression used to describe an event. At one extreme, events not perceived to be decomposable into salient subevents are referred to by monomorphemic verbs, as seen from examples (3-4) involving the verbs 'weave' and 'husk'. Cut and break-type events which are composed of two tightly integrated subevents - a causal event directed at achieving some effect which would not otherwise come about-are referred to by bimorphemic forms which nevertheless qualify as single verbs, while the independence of the elements making up the expression increases with the perceived independence of the constituent subevents.

Secondly, the status of the distinction between "verbs of breaking" and "verbs of cutting", and the conceptual distinctions underlying it, is called into question by the relationship between transitive $\mathrm{C} \& \mathrm{~B}$ forms and their inchoative counterparts in Äiwoo. Languages with bimorphemic C\&B verbs are recognised as forming a class of their own with respect to this distinction (Majid et al. 2007, Bohnemeyer 2007); but they are also predicted not to allow inchoative alternations in this domain. In Äiwoo, firstly, while it is possible to classify many of the transitive forms semantically as involving either events of "cutting" or of "breaking", the possibility of combining, in principle, any "cause" morpheme with any "effect" morpheme gives rise to a number of semantically "in-between" forms. Is for instance längii "smash by striking with the edge of a knife' an instance of "cutting" or of "breaking"? An English speaker, if forced to describe such an event, would probably opt for break 
rather than cut, conceivably on the basis of the parameter of "predictability of locus of separation" (Majid et al. 2007: 142): when striking a fragile object with a knife, even though the locus of impact may be accurately predicted, the lines along which the object will break may not. Äiwoo speakers, by contrast, are not required to make a choice in this regard, but can include both the act performed and its effect, capturing both the similarities with prototypical cutting and with prototypical breaking in a single form.

This example should not, however, be taken to imply that the predictability of the locus of separation is unequivocally encoded by the "effect" morpheme in Äiwoo C\&B forms. Consider the contrast between täki 'cut (a stick or other rigid object)' vs. baki 'break (a stick or other rigid object)'. The first form describes an event for which the locus of separation can be predicted with great precision, as $t \ddot{a}$ - forms are used for events where a knife is applied to an object in a sawing motion. The predictability is somewhat less for baki, where it can only be predicted that the stick will snap somewhere along its length. Thus the semantic parameters of the overall event cannot be rigidly divided into those contributed by the "cause" morpheme and those contributed by the "effect" morpheme, but arise only in the interplay between the two. This is another reason to consider Äiwoo C\&B forms to be lexical items in their own right, and it is further evidence that a sharp line between "cut verbs" on the one hand and "break verbs" on the other cannot be drawn in Äiwoo, since a single C\&B forms may encode properties characteristic of both typical cutting and typical breaking events.

Finally, the use of the inchoative derivation demonstrates that the lack of a systematic distinction between cut verbs and break verbs does not preclude the participation of verbs of targeted destruction in argument-structure alternations. The Äiwoo bo- forms simply specify the effect undergone by the object, while leaving open the type of event which caused the effect. That is, the distinction made in the transitive verb forms between effects brought about by different types of targeted actions is simply neutralised in the inchoative forms.

In sum, Äiwoo illustrates the complexity of the cognitive domain of cutting and breaking events and the range of strategies that may be employed by a language in describing them. It shows that lexicalisation may clearly be a matter of degree, and that the degree to which an event is construed as being constituted by independent subevents vs. subevents which cannot occur independently may be directly reflected in the type of formal expression a language provides to describe it. Furthermore, it suggest that the distinction between "cut" expressions and "break" expressions, assumed in some of the literature to be a fairly straightforward bipartition, may in fact be more of a cline, not just from the perspective of the various parameters relevant for distinguishing between "cut and break" expressions crosslinguistically, but within a single language. 


\begin{abstract}
Abbreviations
A transitive subject, AUG augmented number, CONJ conjunction, DEIC deictic particle, DEM demonstrative, DIR directional, DIST distal, GEN general, F female, IPFV imperfective, INCH inchoative, IRR irrealis, LOC locative, MIN minimal number, NEG negation, NMLZ nominaliser, $\mathrm{O}$ transitive object, OBL.PRO oblique pro-form, PFV perfective, PH phasal aspect, POSS possessive, PROX proximal, RED reduplication, $\mathrm{S}$ intransitive subject, STR semitransitive, TR transitive, UA unit-augmented number.
\end{abstract}

\title{
References
}

Bohnemeyer, Jürgen. 2007. Morpholexical Transparency and the argument structure of verbs of cutting and breaking. Cognitive Linguistics 18(2). 153-177.

Bohnemeyer, Jürgen, Nicholas J. Enfield, James Essegbey, Iraide Ibarretxe-Antuñano, Sotaro Kita, Friederieke Lüpke \& Felix K. Ameka. 2007. Principles of event segmentation in language: The case of motion events. Language 83(2). 495-532.

Bowerman, Melissa \& Asifa Majid. 2003. Kids' cut \& break. In Nick J. Enfield (ed.), Field Research Manual 2003 Part I: Multimodal Interaction, Space, Event Representation, 70-71. Nijmegen: Max Planck Institute for Psycholinguistics.

Chen, Jidong. 2007. 'He cut-break the rope': Encoding and categorising cutting and breaking events in Mandarin. Cognitive Linguistics 18(2). 273-285.

DeLancey, Scott. 1999. Lexical prefixes and the bipartite stem construction in Klamath. International Journal of American Linguistics 65(1). 55-83.

Dixon, R. M. W. \& Alexandra Y. Aikhenvald. 2002. Word: A typological framework. In R. M. W. Dixon \& Alexandra Y. Aikhenvald (eds.), Word: A cross-Linguistic Typology, 1-41. Cambridge: Cambridge University Press.

Guerssel, Mohamed, Kenneth Hale, Mary Laughren, Beth Levin \& Josie White Eagle. 1985. A crosslinguistic study of transitivity alternations. In William H. Eilfort, Paul D. Kroeber \& Karen L. Peterson (eds.), Papers from the Parasession on Causatives and Agentivity at the 21st Regional Meeting, 48-63. Chicago: CLS.

Hale, Kenneth L. \& Samuel J. Keyser. 1987. A view from the middle. Lexicon Project Working Papers 10. Cambridge, MA: Center for Cognitive Science, MIT Press.

Haspelmath, Martin. 1993. More on the typology of inchoative/causative verb alternations. In Bernard Comrie \& Maria Polinsky (eds.), Causatives and Transitivity, 87-120. Amsterdam: John Benjamins.

Haspelmath, Martin. 2002. Understanding Morphology. London: Arnold.

Koptjevskaja-Tamm, Maria, Martine Vanhove \& Peter Koch. 2007. Typological approaches to lexical semantics. Linguistic Typology 11(1). 159-185.

Majid, Asifa \& Melissa Bowerman (eds.). 2007. Cutting and breaking events: A crosslinguistic perspective [Special issue]. Cognitive Linguistics 18(2).

Majid, Asifa, Melissa Bowerman, Miriam van Staden \& James S. Boster. 2007. The semantic categories of cutting and breaking events: A crosslinguistic perspective. Cognitive Linguistics 18(2). 133-152.

Margetts, Anna. 2005. Positional slots in Saliba complex verbs. Oceanic Linguistics 44(1). 65-89.

Næss, Åshild. 2006. Bound nominal elements in Äiwoo: A reappraisal of the "multiple noun class systems". Oceanic Linguistics 45(2). 269-296.

Næss, Åshild \& Brenda H. Boerger. 2008. Reefs-Santa Cruz as Oceanic: Evidence from the verb complex. Oceanic Linguistics 47(1). 185-212. 
Næss, Åshild \& Mathias Jenny. 2011. Who changes language? Bilingualism and structural change in Burma and the Reef Islands. Journal of Language Contact 4. 217-249.

Pawley, Andrew. 2003. Grammatical categories and grammaticalisation in the Oceanic verb complex. In Anastasia Riehl \& Tess Savella (eds), Cornell Working Papers in Linguistics 19, 103188. Ithaca: Cornell University.

Ross, Malcolm \& Åshild Næss. 2007. An Oceanic origin for Äiwoo, the language of the Reef Islands? Oceanic Linguistics 46(2). 456-498.

van Staden, Miriam, Gunter Senft, Nick Enfield, \& Jürgen Bohnemeyer. 2001. Staged Events. In Stephen C. Levinson and Nick Enfield (eds.), Manual for the Field Season 2001, 115-125. Nijmegen: Max Planck Institute for Psycholinguistics. Available online at http://fieldmanuals. mpi.nl/volumes/2001/staged-events/ [last accessed December 2011].

Warren, Beatrice. 1990. The importance of combining forms. In Wolfgang U. Dressler, Hans C. Luschützky, Oskar E. Pfeiffer \& John R. Rennison (eds), Contemporary Morphology, 111-132. Berlin/New York: Mouton de Gruyter. 
Copyright of Cognitive Linguistics is the property of De Gruyter and its content may not be copied or emailed to multiple sites or posted to a listserv without the copyright holder's express written permission. However, users may print, download, or email articles for individual use. 